\title{
Kidney health for everyone everywhere- from prevention to detection and equitable access to care
}

\author{
Philip KT Li $i^{1 *}$ \#, MD, FRCP, Guillermo Garcia-Garcia ${ }^{2 \#, ~ M D, ~ S F ~ L u i ~}{ }^{3 \#, ~ M B, ~ C h B, ~ F R C P, ~ S h a r o n ~ A n d r e o l i ~}{ }^{4 \#, ~ M D, ~}$ \\ Winston WS Fung ${ }^{1}$, MB BChir, MRCP, Anne Hradsky ${ }^{5}$, MA, Latha Kumaraswami ${ }^{6}$, BA, \\ Vassilios Liakopoulos ${ }^{7 \#,}$ MD, PhD, Ziyoda Rakhimova ${ }^{5}$, BSc, Gamal Saadi ${ }^{8 \#, ~ M D, ~ L u i s a ~ S t r a n i ~}{ }^{5 \#}$, ISN, \\ Ifeoma Ulasi ${ }^{9}$, MB, BS, FWACP, Kamyar Kalantar-Zadeh ${ }^{10 * \#, ~ M D, ~ P h D ; ~}$ \\ for the World Kidney Day Steering Committee \\ ${ }^{1}$ Department of Medicine and Therapeutics, Carol and Richard Yu Peritoneal Dialysis Research Centre, Prince of Wales Hospital, The \\ Chinese University of Hong Kong, Hong Kong \\ ${ }^{2}$ Nephrology Service, Hospital Civil de Guadalajara Fray Antonio Alcalde, University of Guadalajara Health Sciences Center, \\ Guadalajara, Mexico \\ ${ }^{3}$ Division of Health System, Policy and Management, Jockey Club School of Public Health and Primary Care, The Chinese University of \\ Hong Kong, Hong Kong \\ ${ }^{4}$ James Whitcomb Riley Hospital for Children, Indiana University School of Medicine, Indianapolis, United States \\ ${ }^{5}$ World Kidney Day Office, Brussels, Belgium \\ ${ }^{6}$ TANKER Foundation, Chennai, India \\ ${ }^{7}$ Division of Nephrology and Hypertension, First Department of Internal Medicine, AHEPA Hospital, Aristotle University of Thessaloniki, \\ Thessaloniki, Greece \\ ${ }^{8}$ Nephrology Unit, Department of Internal Medicine, Faculty of Medicine, Cairo University, Giza, Egypt \\ ${ }^{9}$ Renal Unit, Department of Medicine, College of Medicine, University of Nigeria, Ituku-Ozalla, Enugu, Nigeria \\ ${ }^{10}$ Division of Nephrology and Hypertension and Kidney Transplantation, University of California Irvine School of Medicine, Orange, \\ California, United States \\ *Corresponding authors: philipli@cuhk.edu.hk; kkz@uci.edu \\ \# Members of the World Kidney Day Steering Committee
}

Hong Kong Med J 2020;26:8.e1-9

https://doi.org/10.12809/hkmj198292

\section{Introduction}

Around 850 million people are currently affected by different types of kidney disorders. ${ }^{1} \mathrm{Up}$ to one in 10 adults worldwide has chronic kidney disease (CKD), which is invariably irreversible and mostly progressive. The global burden of CKD is increasing, and CKD is projected to become the fifth most common cause of years of life lost globally by $2040 .^{2}$ If CKD remains uncontrolled and if the affected person survives the ravages of cardiovascular and other complications of the disease, CKD progresses to end-stage renal disease (ESRD), where life cannot be sustained without dialysis therapy or kidney transplantation. Hence, CKD is a major cause of catastrophic health expenditure. ${ }^{3}$ The costs of dialysis and transplantation consume $2 \%$ to $3 \%$ of the annual healthcare budget in high-income countries, and spent on $<0.03 \%$ of the total population of these countries. ${ }^{4}$

Importantly, however, kidney disease can be prevented and progression to ESRD can be delayed with appropriate access to basic diagnostics and early treatment including lifestyle modifications and nutritional interventions. ${ }^{4-8}$ Despite this, access to effective and sustainable kidney care remains highly inequitable across the world, and kidney disease a low health priority in many countries. Kidney disease is crucially missing from the international agenda for global health. Notably absent from the impact indicators for the Sustainable Development Goal Goal 3. Target 3.4: "By 2030, reduce by one third premature mortality from non-communicable diseases (NCDs) through prevention and treatment and promote mental health and well-being" and from the latest iteration of the United Nations Political Declaration on NCDs, kidney diseases urgently need to be given political attention, priority, and consideration. ${ }^{9}$ Current global political commitments on NCDs focus largely on four main diseases: cardiovascular disease (CVD), cancer, diabetes, and chronic respiratory diseases. Yet, it is estimated that $55 \%$ of the global NCD burden is attributed to diseases outside of this group. ${ }^{10}$ Furthermore, kidney disease frequently co-exists with one or more of the above four major NCDs, leading to worse health outcomes. Chronic kidney disease is a major risk factor for heart disease and cardiac death, as well as for infections such as tuberculosis, and is a major complication of other preventable and treatable conditions including diabetes, hypertension, human immunodeficiency virus, and hepatitis. ${ }^{4-7}$ As the Sustainable Development Goals and Universal 
Health Coverage agendas progress and provide a platform for raising awareness of NCD healthcare and monitoring needs, targeted action on kidney disease prevention should become integral to the global policy response. ${ }^{1}$ The global kidney health community calls for the recognition of kidney disease and effective identification and management of its risk factors as a key contributor to the global NCD burden and the implementation of an integrated and people-centred approach to care.

\section{Definition and classification of chronic kidney disease prevention}

According to the expert definitions including the Centers for Disease Control and Prevention, ${ }^{11}$ the term "prevention" refers to activities that are typically categorised by the following three definitions: (1) primary prevention, which implies intervening before health effects occur in an effort to prevent the onset of illness or injury before the disease process begins; (2) secondary prevention, which suggests preventive measures that lead to early diagnosis and prompt treatment of a disease to prevent more severe problems developing and includes screening to identify diseases in the earliest stages; and (3) tertiary prevention, which indicates managing disease after it is well established in order to control disease progression and the emergence of more severe complications, which is often by means

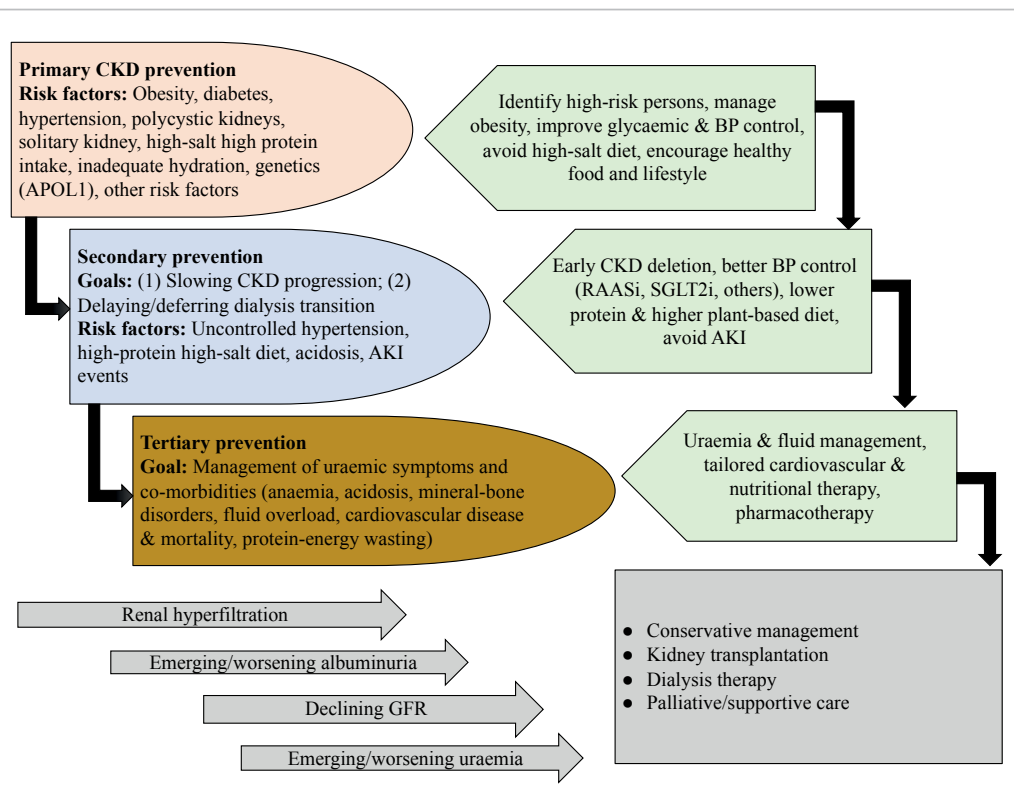

FIG. Overview of the preventive measures in chronic kidney disease to highlight the similarities and distinctions pertaining to primary, secondary, and tertiary preventive measures and their intended goals

Abbreviations: $\mathrm{AKI}=$ acute kidney injury; $\mathrm{APOLI}=$ apolipoprotein I; $\mathrm{BP}=$ blood pressure; $\mathrm{CKD}=$ chronic kidney disease; GFR = glomerular filtration rate; $\mathrm{RAASi}=$ renin-angiotensin-aldosterone system inhibitors; SGLT2i = sodium-glucose transport protein 2 inhibitor of targeted measures such as pharmacotherapy, rehabilitation, and screening for and management of complications. These definitions have an important bearing on the prevention and management of the CKD, and accurate identification of risk factors that cause CKD or lead to faster progression to renal failure as shown in the Figure are relevant in health policy decisions and health education and awareness related to CKD. ${ }^{12}$

\section{Primary prevention of chronic kidney disease}

The incidence and prevalence of CKD have been rising worldwide. ${ }^{13}$ This primary level of prevention requires awareness of modifiable CKD risk factors and efforts to focus healthcare resources on those patients who are at the highest risk of developing new onset or de novo CKD.

Measures to achieve effective primary prevention should focus on the two leading risk factors for CKD including diabetes mellitus and hypertension. Evidence suggests that an initial mechanism of injury is renal hyperfiltration with seemingly elevated glomerular filtration rate (GFR), above normal ranges. This is often the result of glomerular hypertension that is often seen in patients with obesity or diabetes mellitus, but it can also occur after high dietary protein intake. ${ }^{8}$ Other CKD risk factors include polycystic kidneys or other congenital or acquired structural anomalies of the kidney and urinary tracts, primary glomerulonephritis, exposure to nephrotoxic substances or medications (such as nonsteroidal anti-inflammatory drugs), having one single kidney, eg, solitary kidney after cancer nephrectomy, high dietary salt intake, inadequate hydration with recurrent volume depletion, heat stress, exposure to pesticides and heavy metals (as has been speculated as the main cause of Mesoamerican nephropathy), and possibly high protein intake in those at higher risk of CKD. ${ }^{8}$ Among non-modifiable risk factors are advancing age and genetic factors such as apolipoprotein 1 gene that is mostly encountered in those with sub-Saharan African ethnicity, especially among African Americans. Certain disease states may cause de novo CKD such as cardiovascular and atheroembolic diseases (also known as secondary cardiorenal syndrome) and liver diseases (hepatorenal syndrome). Some of the risk factors of CKD are shown in the Table.

Among measures to prevent the emergence of de novo CKD are screening efforts to identify and treat patients at high risk of CKD, especially those with diabetes mellitus and hypertension. Hence, targeting primordial risk factors of these two conditions including metabolic syndrome and overnutrition is relevant to primary CKD prevention as is correcting obesity. ${ }^{14}$ Promoting healthier lifestyle is an important means to that end including 
TABLE. Risk factors for de novo CKD and pre-existing CKD progression

\begin{tabular}{|c|c|c|}
\hline Risk factor* & Contribution to de novo CKD & Contribution to CKD progression \\
\hline Diabetes mellitus & $\sim 50 \%$ of all CKDs & $\begin{array}{l}\text { Poor control can accelerate loss of renal } \\
\text { function }\end{array}$ \\
\hline Hypertension & $\sim 25 \%$ of all CKDs & $\begin{array}{l}\text { Effective blood pressure control was } \\
\text { associated with a low rate of renal decline }\end{array}$ \\
\hline Obesity & $10 \%-20 \%$ & \\
\hline Age & $\begin{array}{l}\text { Seen with advancing age, especially in the } \\
\text { setting of co-morbid conditions }\end{array}$ & $\begin{array}{l}\text { Some suggests that older patients with CKD } \\
\text { may have slower progression }\end{array}$ \\
\hline $\begin{array}{l}\text { Race, genetics, and other hereditary factors } \\
\text { - APOL1 gene } \\
\text { - Hereditary nephritis (Alport's) }\end{array}$ & $\begin{array}{l}\text { Common among those with African American } \\
\text { ancestors }\end{array}$ & APOL1 group have higher risk of renal decline \\
\hline $\begin{array}{l}\text { Acute glomerulonephritis } \\
\text { - Post-infectious } \\
\text { - Rapidly progressive }\end{array}$ & $<10 \%$ & $\begin{array}{l}\text { Recurrent glomerulonephritis or exacerbation } \\
\text { of proteinuria }\end{array}$ \\
\hline Polycystic kidney disorders & $<10 \%$, family history of cystic kidney disorders & \\
\hline $\begin{array}{l}\text { Acute kidney injury } \\
\text { - Acute tubular necrosis } \\
\text { - Acute interstitial nephritis }\end{array}$ & $\begin{array}{l}\text { Repeated acute kidney injury bouts can cause } \\
\text { CKD }\end{array}$ & $\begin{array}{l}\text { Repeated acute kidney injury bouts can } \\
\text { accelerate CKD progression }\end{array}$ \\
\hline $\begin{array}{l}\text { Autoimmune disorders } \\
\text { - Lupus erythematosus } \\
\text { - Other connective tissue disorders }\end{array}$ & $\begin{array}{l}\text { Lupus erythematosus is well known to cause } \\
\text { de novo CKD with nephritis }\end{array}$ & $\begin{array}{l}\text { Repeated flare of lupus nephritis can lead to } \\
\text { CKD progress }\end{array}$ \\
\hline $\begin{array}{l}\text { Pharmacologic } \\
\text { - Medications causing interstitial nephritides } \\
\text { (NSAIDS, CNI, chemotherapy, PPI, etc) or } \\
\text { acute tubular necrosis (aminoglycosides) } \\
\text { - Herbs and herbal medication }\end{array}$ & $\begin{array}{l}\text { Variable, eg, in Taiwan, Chinese herb } \\
\text { nephropathy may be an important contributor }\end{array}$ & \\
\hline $\begin{array}{l}\text { Environmental } \\
\text { - Heavy metal exposure }\end{array}$ & Rare & \\
\hline $\begin{array}{l}\text { Acquired or congenital solitary kidney } \\
\text { - Cancer, donor or traumatic nephrectomy } \\
\text { - Congenital solitary kidney, unilateral atrophic } \\
\text { kidney }\end{array}$ & & $\begin{array}{l}\text { Compensatory glomerular hyperfiltration can } \\
\text { cause damage to the remaining solitary kidney, } \\
\text { especially with there is other risk factors } \\
\text { concomitantly }\end{array}$ \\
\hline $\begin{array}{l}\text { Acquired urinary tract disorders and } \\
\text { obstructive nephropathy }\end{array}$ & $\begin{array}{l}\text { Benign prostate hypertrophy in men } \\
\text { Gynaecological cancers in women }\end{array}$ & \\
\hline $\begin{array}{l}\text { Congenital anomalies of the kidney and urinary } \\
\text { tract }\end{array}$ & Mostly in children and young adults & \\
\hline $\begin{array}{l}\text { Inadequate fluid intake } \\
\text { - Mesoamerican nephropathy } \\
\text { - Others }\end{array}$ & $\begin{array}{l}\text { Unknown risk, but high prevalence is } \\
\text { suspected in central America }\end{array}$ & $\begin{array}{l}\text { Whereas in earlier CKD stages adequate } \\
\text { hydration is important to avoid pre-renal acute } \\
\text { kidney injury bouts, higher fluid intake in } \\
\text { more advanced CKD may increase the risk of } \\
\text { hyponatraemia }\end{array}$ \\
\hline High protein intake & $\begin{array}{l}\text { Unknown risk, recent data suggest higher CKD } \\
\text { risk or faster CKD progression with high-protein } \\
\text { diet, in particular from animal sources }\end{array}$ & $\begin{array}{l}\text { Higher protein intake can accelerate the rate of } \\
\text { CKD progression }\end{array}$ \\
\hline Cardiovascular diseases (cardiorenal) & Ischaemic nephropathy & \\
\hline Liver disease (hepatorenal) & NASH cirrhosis, viral hepatitis & \\
\hline
\end{tabular}

Abbreviations: APOLI = apolipoprotein I; CKD = chronic kidney disease; CNI = calcineurin inhibitor; NASH = non-alcoholic steatohepatitis; NSAIDs = nonsteroidal anti-inflammatory drugs; PPI = proton pump inhibitor

* Many of these risk factors contribute to both de novo CKD and its faster progression and hence are relevant to both primary and secondary prevention

physical activity and healthier diet. The latter should be effective in preventing diabetic and hypertensive be based on more plant-based foods with less meat, nephropathies. A recent expert panel suggested less sodium intake, more complex carbohydrates that patients with solitary kidney should avoid high with higher fibre intake, and less saturated fat. In protein intake $>1 \mathrm{~g} / \mathrm{kg}$ body weight per day. ${ }^{15}$ Obesity those with hypertension and diabetes, optimising should be avoided, and weight reduction strategies blood pressure and glycaemic control has shown to should be considered. ${ }^{14}$ 


\section{Secondary prevention in chronic kidney disease}

Evidence suggests that among patients with CKD, the vast majority have an early stage of the disease, ie, CKD stages 1 and 2 with microalbuminuria (30-300 $\mathrm{mg} /$ day) or CKD stage 3B (ie, estimated GFR between 45 and $\left.60 \mathrm{~mL} / \mathrm{min} / 1.73 \mathrm{~m}^{2}\right) .{ }^{16}$ In these patients with pre-existing disease, the secondary prevention of CKD has the highest priority. For these earlier stages of CKD, the main goal of kidney health education and clinical interventions is how to slow disease progression. Uncontrolled or poorly controlled hypertension is one of the most established risk factors for faster CKD progression. The underlying pathophysiology of faster CKD progression relates to ongoing damage to the kidney structure and loss of nephrons with worsening interstitial fibrosis as it happens with sustained hypertension. A target of blood pressure of $<130 / 80 \mathrm{mmHg}$ should be recommended.

The cornerstone of the pharmacotherapy in secondary prevention is the use of angiotensin pathway modulators, also known as reninangiotensin-aldosterone system inhibitors. These drugs reduce both systemic blood pressure and intraglomerular pressure by opening efferent arterioles of the glomeruli, hence, leading to longevity of the remaining nephrons. Low-protein diet appears to have a synergistic effect on reninangiotensin-aldosterone system inhibitor therapy ${ }^{17}$ In terms of the potential effect of controlling glycaemic status and correcting obesity on the rate of CKD progression, there are mixed data. However, recent data suggest that a new class of antidiabetic medications known as sodiumglucose cotransporter-2 inhibitors can slow CKD progression, but this effect may not be related to glycaemic modulation of the medication. The CREDENCE study demonstrated that the risk of renal failure is significantly lower in the canagliflozin group than the placebo group..$^{18}$ Another emerging antidiabetic agent in delaying kidney injury is the glucagon-like peptide-1 receptor agonist. ${ }^{19} \mathrm{~A}$ glycated haemoglobin level of $<7 \%$ should be the goal. Whereas acute kidney injury (AKI) may or may not cause de novo CKD, AKI events that are superimposed on pre-existing CKD may accelerate disease progression. ${ }^{20}$ In particular, judicious use of nephrotoxic agents (such as iodine-based contrast, chemotherapeutic agents and immunomodulatory drugs) in patients with pre-existing CKD is imperative in order to prevent new AKI. A relatively recent case of successful secondary prevention that highlights the significance of implementing preventive strategies in CKD is the use of a vasopressin V2-receptor antagonists in autosomal dominant polycystic kidney disease. ${ }^{21}$

\section{Tertiary prevention in chronic kidney disease}

In patients with advanced CKD, management of uraemia and related co-morbid conditions such as anaemia, mineral and bone disorders, and CVD is of high priority, so that these patients can continue to achieve the highest longevity. These measures can be collectively referred to as tertiary prevention of CKD. In these patients, CVD burden is exceptionally high, especially if they have underlying diabetes or hypertension, while they often do not follow other traditional profile of cardiovascular risk such as obesity or hyperlipidaemia. Indeed, in these patients, a so-called reverse epidemiology exists, in which hyperlipidaemia and obesity appear to be protective at this advanced stage of CKD. This could be due to the overshadowing impact of the proteinenergy wasting that happens more frequently with worsening uraemia and which is associated with weight loss and poor outcomes including CVD and death. Whereas many of these patients, if they survive ravages of protein-energy wasting and CVD, will eventually receive renal replacement therapy in form of dialysis therapy or kidney transplantation, a new trend is emerging to maintain them longer without dialysis by implementing conservative management of CKD. However, in some with additional comorbidities such as metastatic cancers, palliative measures with supportive care can be considered.

\section{Identification of chronic kidney disease}

The lack of awareness of CKD around the world is one of the reasons for late presentation of CKD in both developed and developing economies. ${ }^{22-24}$ The overall CKD awareness among the general population and even high cardiovascular risk groups across 12 low-income and middle-income countries (LMIC) was $<10 \% .{ }^{24}$

Given its asymptomatic nature, screening of CKD plays an important role in early detection. Consensus and positional statements have been published by the International Society of Nephrology, ${ }^{25}$ National Kidney Foundation, ${ }^{26}$ Kidney Disease Improving Global Outcomes, ${ }^{27}$ NICE Guidelines, ${ }^{28}$ and Asian Forum for Chronic Kidney Disease Initiatives. ${ }^{29}$ There was lack of trials to evaluate screening and monitoring of CKD. ${ }^{30}$ Currently, most will promote a targeted screening approach to early detection of CKD. Some of the major groups at risk for targeted screening include patients with diabetes; hypertension; patients with a family history of CKD; patients taking potentially nephrotoxic drugs, herbs, substances, or indigenous medicines; patients with a history of AKI; and patients aged $>65$ years. ${ }^{29,31}$ Chronic kidney disease can be detected with two simple tests: a urine test 
for the detection of proteinuria and a blood test to estimate the GFR. ${ }^{26,29}$

Given that currently a population screening for CKD is not recommended and it was claimed that it might add unintended harm to the general population being screened, ${ }^{30}$ there is no speciality society or preventive services group which recommends general screening. ${ }^{32}$ Low-to-middleincome countries are ill-equipped to deal with the devastating consequences of CKD, particularly the late stages of the disease. There are suggestions that screening should primarily include high-risk patients, but also extend to those with suboptimal levels of risk, eg, pre-diabetes and prehypertension. ${ }^{33}$

\section{Cost-effectiveness of early detection programmes}

Universal screening of the general population would be time-consuming, expensive, and has been shown to be not cost-effective. Unless selectively directed towards high-risk groups, such as the case of unknown cause of CKD in disadvantaged populations, ${ }^{34}$ according to a cost-effectiveness analysis using a Markov decision analytic model, population-based dipstick screening for proteinuria has an unfavourable cost-effectiveness ratio. ${ }^{35} \mathrm{~A}$ more recent Korean study confirmed that their National Health Screening Program for CKD is more cost-effective for patients with diabetes or hypertension than the general population. ${ }^{36}$ From an economic perspective, screening CKD by detection of proteinuria was shown to be cost-effective in patients with hypertension or diabetes in a systematic review. ${ }^{37}$ The incidence of $C K D$, rate of progression, and effectiveness of drug therapy were major drivers of cost-effectiveness and thus CKD screening may be more cost-effective in populations with higher incidences of CKD, rapid rates of progression, and more effective drug therapy.

\section{Rational approach to chronic kidney disease early detection}

The approach towards CKD early detection will include the decision for frequency of screening, who should perform the screening and intervention after screening. ${ }^{23}$ Screening frequency for targeted patients should be yearly if no abnormality is detected on initial evaluation. This is in line with the Kidney Disease Improving Global Outcomes resolution that the frequency of testing should be according to the target group to be tested and generally needs not be more frequent than once per year. ${ }^{27}$ Who should perform the screening is always a question especially when the healthcare professional availability is a challenge in lowerincome economies. Physicians, nurses, paramedical staff, and other trained healthcare professionals are eligible to do the screening tests. Intervention after screening is also important and patients detected to have CKD should be referred to primary care and general physicians with experience in management of kidney disease for follow-up. A management protocol should be provided to primary care and general physicians. Further referral to nephrologists for management will be based on the well-defined protocols..$^{24,27,29}$

\section{Integration of chronic kidney disease prevention into national non-communicable disease programmes}

Given the close links between CKD and other NCDs, it is critical that CKD advocacy efforts be aligned with existing initiatives concerning diabetes, hypertension, and CVD, particularly in LMIC. Some countries and regions have successfully introduced CKD prevention strategies as part of their NCD programmes. As an example, in 2003, a kidney health promotion programme was introduced in Taiwan, with its key components including a ban on herbs containing aristolochic acid, public awareness campaigns, patient education, funding for CKD research, and the setting up of teams to provide integrated care. ${ }^{38}$ In Cuba, the Ministry of Public Health has implemented a national programme for the prevention of CKD. Since 1996 the programme has followed several steps: (1) analysis of the resources and health situation in the country; (2) epidemiological research to define the burden of CKD; and (3) continuing education for nephrologists, family doctors, and other health professionals. The main goal has been to bring nephrology care closer to the community through a regional redistribution of nephrology services and joint treatment of patients with CKD by primary healthcare physicians and nephrologists. ${ }^{39}$ The integration of CKD prevention into NCD programme has resulted in the reduction of renal and cardiovascular risks in the general population. Main outcomes have been the reduction in the prevalence of risk factors, such as low birth weight, smoking, and infectious diseases. There has been an increased rate of the diagnosis of diabetes and of glycaemic control, as well as an increased diagnosis of patients with hypertension, higher prescription use of renoprotective treatment with angiotensin-converting enzyme inhibitor, and higher rates of blood pressure control..$^{40}$ Recently, the United States Department of Health and Human Services has introduced an ambitious programme to reduce the number of Americans developing ESRD by $25 \%$ by 2030 . The programme, known as the Advancing American Kidney Health initiative, has 
set goals with metrics to measure its success; among them is to put more efforts to prevent, detect, and slow the progression of kidney disease, in part by addressing traditional risk factors such as diabetes and hypertension. To reduce the risk of kidney failure, the programme contemplates advancing public health surveillance and research to identify populations at risk and those in early stages of kidney disease, and to encourage adoption of evidencebased interventions to delay or stop progression to kidney failure. ${ }^{41}$ Ongoing programmes, such as the Special Diabetes Program for Indians, represent an important part of this approach by providing team-based care and care management. After implementation of that programme, the incidence of diabetes-related kidney failure among Indian populations decreased by over $40 \%$ between 2000 and $2015 .^{42}$

\section{Involvement of primary care physicians and other health professionals}

Detection and prevention of CKD programmes require considerable resources both in terms of manpower and funds. Availability of such resources will depend primarily on the leadership of nephrologists. ${ }^{43}$ However, the number of nephrologists is not sufficient to provide renal care to the growing number of patients with CKD worldwide. It has been suggested that most cases of non-progressive CKD can be managed without referral to a nephrologist, and specialist referral can be reserved for patients with an estimated GFR $<30 \mathrm{~mL} / \mathrm{min} / 1.73 \mathrm{~m}^{2}$, rapidly declining kidney function, persistent proteinuria, or uncontrolled hypertension or diabetes. ${ }^{44}$ It has been demonstrated that with an educational intervention the clinical competence of family physicians increases, resulting in preserved renal function in diabetic patients with early renal disease. ${ }^{45}$ The practitioners who received the educational intervention used significantly more angiotensin-converting enzyme inhibitors, angiotensin-receptor blockers, and statins than did practitioners who did not receive it. The results were similar to those found in patients treated by nephrologists. ${ }^{46}$ The role of primary healthcare professionals in the implementation of CKD prevention strategies in LMIC has been recently illustrated. ${ }^{47}$

The e-Learning has become an increasingly popular approach to medical education. Online learning programmes for NCD prevention and treatment, including CKD, have been successfully implemented in Mexico. By 2015, over 5000 health professionals (including non-nephrologists) had been trained using an electronic health education platform. ${ }^{48}$

\section{Shortage of nephrology manpower-implications for prevention}

The resources for nephrology care remain at critical levels in many parts of the world. Even in Western developed countries, nephrologists are frequently in short supply. In a selection of European countries with similar, predominantly public, healthcare systems, there was a substantial variation in the nephrology workforce. Countries such as Italy, Greece, and Spain reported the highest ratios, whereas countries such as Ireland, Turkey, and the United Kingdom had the lowest ratios. ${ }^{49}$ In the United States, the number of nephrologists per 1000 ESRD patients has declined from 18 in 1997 to 14 in $2010 .{ }^{50}$ The situation in the developing world is even worse. With the exception of Nigeria, Sudan, Kenya and South Africa, in many countries of sub-Saharan Africa there are $<10$ nephrologists. The number of nephrology nurses and dialysis technicians is also insufficient. ${ }^{51}$ In Latin America the average number of nephrologists is 13.4 per million population ( $\mathrm{pmp}$ ). However, there is unequal distribution between countries; those with $<10$ nephrologists pmp (Honduras, $2.1 \mathrm{pmp}$; Guatemala, $3.3 \mathrm{pmp}$; and Nicaragua, $4.6 \mathrm{pmp}$ ), and those $>25$ pmp (Cuba, 45.2 pmp; Uruguay, $44.2 \mathrm{pmp}$; and Argentina, $26.8 \mathrm{pmp}) .^{52}$

The causes of this shortage are multiple. Potential contributors to this variation include the increasing burden of CKD, erosion of nephrology practice scope by other specialists, lack of workforce planning in some countries relative to others, and the development of new care delivery models. ${ }^{50} \mathrm{~A}$ novel strategy has been the successful International Society of Nephrology's Fellowship programme. Since its implementation in 1985, over 600 fellows from >83 LMIC have been trained. A significant number of fellowships were undertaken in selected developed centres within the fellow's own region. In a recent survey, $85 \%$ of responding fellows were reemployed by their home institutions..$^{53,54}$

\section{Interdisciplinary prevention approach}

Since 1994, a National Institute of Health consensus advocated for early medical intervention in predialysis patients. Owing to the complexity of care of CKD, it was recommended that patients should be referred to a multidisciplinary team consisting of nephrologist, dietitian, nurse, social worker, and health psychologist, with the aim to reduce predialysis and dialysis morbidity and mortality. ${ }^{55}$ In Mexico, a nurse-led protocol-driven multidisciplinary programme reported better preservation in estimated GFR and a trend in the improvement of quality of care of patients with CKD similar to those reported 
by other multidisciplinary clinic programmes in the developed world. Additionally, more patients started dialysis non-emergently, and some obtained a pre-emptive kidney transplant. For those unable to obtain dialysis or who choose not to, a palliative care programme is now being implemented. ${ }^{56}$ Care models supporting primary care providers or allied health workers achieved better effectiveness in slowing kidney function decline when compared to those providing speciality care. Future models should address region-specific causes of CKD, increase the quality of diagnostic capabilities, establish referral pathways, and provide better assessments of clinical effectiveness and cost-effectiveness. ${ }^{57}$

\section{Online educational programmes for chronic kidney disease prevention and treatment}

Whereas it is important to enhance the promotion and implementation of prevention of kidney disease and kidney failure among healthcare professionals, it is equally important to promote prevention with education programmes for those at risk of kidney disease and kidney failure, and with the general population at large. It is a stepwise process, from awareness, through engagement, participation, and empowerment, to partnership. As highlighted above, in general, the health literacy of the general population is low. Awareness and understanding of kidney disease are inadequate. Education is key to engaging patients with kidney disease. It is the path to self-management and patient-centred care. Narva et $\mathrm{al}^{58}$ found patient education is associated with better patient outcomes. Obstacles include the complex nature of kidney disease information, low baseline awareness, limited health literacy and numeracy, limited availability of CKD information, and lack of readiness to learn. New education approaches should be developed through research and quality improvement efforts. Schatell ${ }^{59}$ found that webbased kidney education is helpful in supporting patient self-management. The internet offers a wealth of resources on education. Understanding the types of internet sources that patients with CKD use today can help renal professionals to point patients in the right direction. It is important that reputable healthcare organisations, preferably at a national level, facilitate users to have easier access to health information on their websites (as shown in online supplementary Appendix). The mode of communication currently used by patients and the population at large is through the internet-websites, portals, and other social media, such as Facebook and Twitter. There are also free apps on popular mobile devices providing education on kidney disease. There is no shortage of information on the internet.
The challenge is how to effectively push important healthcare information in a targeted manner, and to facilitate users seeking information in their efforts to pull relevant and reliable information from the internet. It is important that health information is relevant for the condition (primary, secondary or tertiary prevention), and offered at the right time to the right recipient. It is possible, with the use of information technology and informatics, to provide relevant and targeted information for patients at high risk, coupling the information based on diagnosis and drugs prescribed. Engagement of professional society resources and patient groups is a crucial step to promote community partnership and patient empowerment on prevention. Additional resources may be available from charitable and philanthropic organisations.

\section{Renewed focus on prevention, awareness-raising, and education}

Given the urgency for increased education and awareness on the importance of the preventive measures, we suggest the following goals to redirect the focus on plans and actions:

1. Empowerment through health literacy in order to develop and support national campaigns that bring public awareness to prevention of kidney disease.

2. Population-based approaches to manage key known risks for kidney disease such as blood pressure control, and effective management of obesity and diabetes.

3. Implementation of the World Health Organization 'Best Buys' approach including screening of at-risk populations for CKD, universal access to essential diagnostics of early CKD, availability of affordable basic technologies and essential medicines and task shifting from doctors to frontline healthcare workers to more effectively target the progression of CKD and other secondary preventative approaches.

To that end, the motto "Kidney Health for Everyone, Everywhere" is more than a tagline or wishful thinking. It is a policy imperative which can be successfully achieved if policy-makers, nephrologists, and healthcare professionals place prevention and primary care for kidney disease within the context of their Universal Health Coverage programmes.

\section{Author contributions}

PKT Li and K Kalantar-Zadeh serve as the corresponding authors. All the authors contributed equally otherwise. All authors had full access to the data, contributed to the study, approved the final version for publication, and take responsibility for its accuracy and integrity. 


\section{Conflicts of interest}

All authors have disclosed no conflicts of interest.

\section{Funding/support}

This editorial received no specific grant from any funding agency in the public, commercial, or not-for-profit sectors.

\section{Declaration}

This article was originally published in Kidney International, volume 97, pages 226-232, Copyright World Kidney Day Steering Committee (2020), and reprinted concurrently in several journals. The articles cover identical concepts and wording but vary in minor stylistic and spelling changes, detail, and length of manuscript in keeping with each journal's style. Any of these versions may be used in citing this article.

\section{References}

1. International Society of Nephrology. 2019 United Nations high level meeting on universal health coverage: moving together to build kidney health worldwide. Available from: https://www.theisn.org/images/Advocacy_4_pager_2019_ Final_WEB_pagebypage.pdf. Accessed 20 Jul 2019.

2. Foreman KJ, Marquez N, Dolgert A, et al. Forecasting life expectancy, years of life lost, and all-cause and cause-specific mortality for 250 causes of death: reference and alternative scenarios for 2016-40 for 195 countries and territories. Lancet 2018;392:2052-90.

3. Essue BM, Laba TL, Knaul F, et al. Economic burden of chronic ill health and injuries for households in low- and middle-income countries. In: Jamison DT, Gelband H, Horton $\mathrm{S}$, et al, editors. Disease Control Priorities Improving Health and Reducing Poverty, 3rd ed. Washington, DC: World Bank; 2018: 121-43.

4. Vanholder R, Annemans L, Brown E, et al. Reducing the costs of chronic kidney disease while delivering quality health care: a call to action. Nat Rev Nephrol 2017;13:393-409.

5. Luyckx VA, Tuttle KR, Garcia-Garcia G, et al. Reducing major risk factors for chronic kidney disease. Kidney Int Suppl (2011) 2017;7:71-87.

6. Luyckx VA, Tonelli M, Stanifer JW. The global burden of kidney disease and the sustainable development goals. Bull World Health Organ 2018;96:414-22D.

7. Tonelli M, Muntner P, Lloyd A, et al. Risk of coronary events in people with chronic kidney disease compared with those with diabetes: a population-level cohort study. Lancet 2012;380:807-14.

8. Kalantar-Zadeh K, Fouque D. Nutritional management of chronic kidney disease. N Engl J Med 2017;377:1765-76.

9. United Nations General Assembly. Political declaration of the third high-level meeting of the General Assembly on the prevention and control of non-communicable diseases. Available from: https://www.un.org/ga/search/view_doc. asp?symbol=A/73/L.2\&Lang=E. Accessed 19 Nov 2019.

10. Lopez AD, Williams TN, Levin A, et al. Remembering the forgotten non-communicable diseases. BMC Med 2014;12:200.

11. Centers for Disease Control and Prevention. At-a-glance: Executive Summary, Picture of America. Available from: https://www.cdc.gov/pictureofamerica. Accessed 19 Nov 2019.

12. Levey AS, Schoolwerth AC, Burrows NR, Williams DE, Stith KR, McClellan W; Centers for Disease Control and
Prevention Expert Panel. Comprehensive public health strategies for preventing the development, progression, and complications of CKD: report of an expert panel convened by the Centers for Disease Control and Prevention. Am J Kidney Dis 2009;53:522-35.

13. Saran R, Robinson B, Abbott KC, et al. US Renal Data System 2018 Annual Data Report: Epidemiology of Kidney Disease in the United States. Am J Kidney Dis 2019;73(3S1):A7-A8.

14. Kovesdy CP, Furth SL, Zoccali C, World Kidney Day Steering Committee. Obesity and kidney disease: hidden consequences of the epidemic. J Ren Nutr 2017;27:75-7.

15. Tantisattamo E, Dafoe DC, Reddy UG, et al. Current management of patients with acquired solitary kidney. Kidney Int Rep 2019;4:1205-18.

16. Webster AC, Nagler EV, Morton RL, Masson P. Chronic kidney disease. Lancet 2017;389:1238-52.

17. Koppe L, Fouque D. The role for protein restriction in addition to renin-angiotensin-aldosterone system inhibitors in the management of CKD. Am J Kidney Dis 2019;73:24857.

18. Perkovic V, Jardine MJ, Neal B, et al. Canagliflozin and renal outcomes in type 2 diabetes and nephropathy. $\mathrm{N}$ Engl J Med 2019;380:2295-306.

19. Greco EV, Russo G, Giandalia A, Viazzi F, Pontremoli R, De Cosmo S. GLP-1 receptor agonists and kidney protection. Medicina (Kaunas) 2019;55(6).pii: E233.

20. Rifkin DE, Coca SG, Kalantar-Zadeh K. Does AKI truly lead to CKD? J Am Soc Nephrol 2012;23:979-84.

21. Torres VE, Chapman AB, Devuyst O, et al. Tolvaptan in patients with autosomal dominant polycystic kidney disease. N Engl J Med 2012;367:2407-18.

22. Verhave JC, Troyanov S, Mongeau F, et al. Prevalence, awareness, and management of CKD and cardiovascular risk factors in publicly funded health care. Clin J Am Soc Nephrol 2014;9:713-9.

23. Chow KM, Szeto CC, Kwan B, Leung CB, Li PK. Public lacks knowledge on chronic kidney disease: telephone survey. Hong Kong Med J 2014;20:139-44.

24. Ene-Iordache B, Perico N, Bikbov B, et al. Chronic kidney disease and cardiovascular risk in six regions of the world (ISN-KDDC): a cross-sectional study. Lancet Glob Health 2016;4:e307-19.

25. Li PK, Weening JJ, Dirks J, et al. A report with consensus statements of the International Society of Nephrology 2004 Consensus Workshop on Prevention of Progression of Renal Disease, Hong Kong, June 29, 2004. Kidney Int Suppl 2005;(94):S2-7.

26. Vassalotti JA, Stevens LA, Levey AS. Testing for chronic kidney disease: A position statement from the National Kidney Foundation. Am J Kidney Dis 2007;50:169-80.

27. Levey AS, Atkins R, Coresh J, et al. Chronic kidney disease as a global public health problem: Approaches and initiatives-a position statement from Kidney Disease Improving Global Outcomes. Kidney Int 2007;72:247-59.

28. Crowe E, Halpin D, Stevens P; Guideline Development Group. Early identification and management of chronic kidney disease: summary of NICE guidance. BMJ 2008;337:a1530.

29. Li PK, Chow KM, Matsuo S, et al. Asian chronic kidney disease best practice recommendations: positional statements for early detection of chronic kidney disease from Asian Forum for Chronic Kidney Disease Initiatives (AFCKDI). Nephrology (Carlton) 2011;16:633-41.

30. Fink HA, Ishani A, Taylor BC, et al. Screening for, monitoring, 
and treatment of chronic kidney disease stages 1 to 3: A systematic review for the U.S. Preventive Services Task Force and for an American College of Physicians Clinical Practice Guideline. Ann Intern Med 2012;156:570-81.

31. Li PK, Ng JK, Cheng YL, et al. Relatives in silent kidney disease screening (RISKS) study: a Chinese cohort study. Nephrology (Carlton) 2017;22 Suppl 4:35-42.

32. Samal L, Linder JA. The primary care perspective on routine urine dipstick screening to identify patients with albuminuria. Clin J Am Soc Nephrol 2013;8:131-5.

33. George C, Mogueo A, Okpechi I, Echouffo-Tcheugui JB, Kengne AP. Chronic kidney disease in low-income to middleincome countries: the case for increased screening. BMJ Glob Health 2017;2:e000256.

34. Gonzalez-Quiroz M, Nitsch D, Hamilton S, et al. Rationale and population-based prospective cohort protocol for the disadvantaged populations at risk of decline in eGFR (CODEGREE). BMJ Open 2019;9:e031169.

35. Boulware LE, Jaar BG, Tarver-Carr ME, Brancati FL, Powe NR. Screening for proteinuria in US adults: A costeffectiveness analysis. JAMA 2003;290:3101-14.

36. Go DS, Kim SH, Park J, Ryu DR, Lee HJ, Jo MW. Cost-utility analysis of the National Health Screening Program for chronic kidney disease in Korea. Nephrology (Carlton) 2019;24:56-64.

37. Komenda P, Ferguson TW, Macdonald K, et al. Costeffectiveness of primary screening for CKD: A systematic review. Am J Kidney Dis 2014;63:789-97.

38. Hwang SJ, Tsai JC, Chen HC. Epidemiology, impact and preventive care of chronic kidney disease in Taiwan. Nephrology (Carlton) 2010;15 Suppl 2:3-9.

39. Almaguer M, Herrera R, Alfonso J, Magrans C, Mañalich R, Martínez A. Primary health care strategies for the prevention of end-stage renal disease in Cuba. Kidney Int Suppl 2005;97:S4-10.

40. Alamaguer-Lopez M, Herrera-Valdez R, Diaz J, Rodriguez O. Integration of chronic kidney disease prevention into noncommunicable disease programs in Cuba. In: GarciaGarcia G, Agodoa LY, Norris KC, editors. Chronic Kidney Disease in Disadvantaged Populations. London: Elsevier Inc; 2017: 357-65.

41. US Department of Health and Human Services. Advancing American Kidney Health. Available from: https://aspe. hhs.gov/pdf-report/advancing-american-kidney-health. Accessed 26 Sep 2019.

42. US Department of Health and Human Services. The Special Diabetes Program for Indians. Estimates of Medicare savings. Available from: https://aspe.hhs.gov/pdf-report/specialdiabetes-program-indians-estimates-medicare-savings. Accessed 26 Sep 2019.

43. Bello AK, Nwankwo E, El Nahas AM. Prevention of chronic kidney disease: a global challenge. Kidney Int Suppl 2005;(98):S11-7.

44. James MT, Hemmelgarn BR, Tonelli M. Early recognition and prevention of chronic kidney disease. Lancet 2010;375:1296309.

45. Cortés-Sanabria L, Cabrera-Pivaral CE, Cueto-Manzano
AM, et al. Improving care of patients with diabetes and CKD: a pilot study for a cluster-randomized trial. Am J Kidney Dis 2008;51:777-88.

46. Martínez-Ramírez HR, Jalomo-Martínez B, Cortés-Sanabria $\mathrm{L}$, et al. Renal function preservation in type 2 diabetes mellitus patients with early nephropathy: a comparative prospective cohort study between primary health care doctors and a nephrologist. Am J Kidney Dis 2006;47:78-87.

47. Cueto-Manzano AM, Martínez-Ramírez HR, CortesSanabria L, Rojas-Campos E. CKD screening and prevention strategies in disadvantaged populations. The role of primary health care professionals. In: Garcia-Garcia G, Agodoa LY, Norrris KC, editors. Chronic Kidney Disease in Disadvantaged Populations. London: Elsevier, Inc; 2017: 329-35.

48. Tapia-Conyer R, Gallardo-Rincon H, Betancourt-Cravioto M. Chronic kidney disease in disadvantaged populations: Online educational programs for NCD prevention and treatment. In: Garcia-Garcia G, Agodoa LY, Norris KC, editors. Chronic Kidney Disease in Disadvantaged Populations. London: Elsevier, Inc; 2017: 337-45.

49. Bello AK, Levin A, Manns BJ, et al. Effective CKD care in European countries: challenges and opportunities for health policy. Am J Kidney Dis 2015;65:15-25.

50. Sharif MU, Elsayed ME, Stack AG. The global nephrology workforce: emerging threats and potential solutions! Clin Kidney J 2016;9:11-22.

51. Naicker S, Eastwood JB, Plange-Rhule J, Tutt RC. Shortage of healthcare workers in sub-Saharan Africa: a nephrological perspective. Clin Nephrol 2010;74 Suppl 1:S129-33.

52. Cusumano AM, Rosa-Diez GJ, Gonzalez-Bedat MC. Latin American Dialysis and Transplant Registry: Experience and contributions to end-stage renal disease epidemiology. World J Nephrol 2016;5:389-97.

53. Feehally J, Brusselmans A, Finkelstein FO, et al. Improving global health: measuring the success of capacity building outreach programs: a view from the International Society of Nephrology. Kidney Int Suppl (2011) 2016;6:42-51.

54. Harris DC, Dupuis S, Couser WG, Feehally J. Training nephrologists from developing countries: does it have a positive impact? Kidney Int Suppl (2011) 2012;2:275-8.

55. Morbidity and mortality of renal dialysis: an NIH consensus conference statement. Consensus Development Conference Panel. Ann Intern Med 1994;121:62-70.

56. Garcia-Garcia G, Martinez-Castellanos Y, Renoirte-Lopez $\mathrm{K}$, et al. Multidisciplinary care for poor patients with chronic kidney disease in Mexico. Kidney Int Suppl (2011) 2013;3:17883.

57. Stanifer JW, Von Isenburg M, Chertow GM, Anand S. Chronic kidney disease care models in low- and middleincome countries: a systematic review. BMJ Glob Health 2018;3:e000728.

58. Narva AS, Norton JM, Boulware LE. Educating patients about CKD: the path to self-management and patient-centered care. Clin J Am Soc Nephrol 2016;11:694-703.

59. Schatell D. Web-based kidney education: supporting patient self-management. Semin Dial 2013;26:154-8. 